\title{
Implementing Enterprise Systems in the Public Sector
}

\author{
Michel L. Ehrenhard \\ University of Twente, The Netherlands
}

\section{INTRODUCTION}

Modernizing public administration requires a new approach to technology. You can no longer rely on rigid, monolithic service systems. You need technology that can increase efficiency, improve economic viability, enhance process transparency, and help you communicate with the public. You need a public sector solution that supports integrated processes, simplifies service-oriented administration and cost management, and distributes the information needed for judicious planning and decision making. (SAP, 2003)

\section{BACKGROUND}

Enterprise systems (ES), also known as enterprise resource planning (ERP) systems, appear to be a dream come true as they promise seamless integration of all the information flowing through an organization: financial and accounting information, human resource information, supply chain information, customer information (Davenport, 1998). The market for ES has grown enormously during the nineties. Most of the Fortune 500 companies have already installed ES (Kumar \& Van Hillegersberg, 2000). For government the promise of ES might even be larger as integrated information flows can support government's processes in numerous ways and help improve service delivery, accountability, and managing for results. As the implementation of ES has proven to be quite difficult due to far-reaching consequences for the organization as a whole, the growing number of government organizations choosing to implement an ES needs to learn from previous experiences. Unfortunately, the scientific literature on ES implementation is mostly limited to the private sector, and as such neglects a substantial part of the organized society. Furthermore, implementation is even more difficult due to the unique nature of government organizations.

The structure of the article is as follows. First, a description of ES is given, as well as the problems that generally surface during the implementation process. Then, public sector issues with information systems imple- mentation are derived from literature on IT in the public sector. Subsequently, the scarce literature in the field of public sector ES implementation is synthesized and discussed. Based on the aforementioned two streams of research and the few studies already conducted, the emerging trends and research opportunities in the field of public sector ES implementation are put forward. Finally, the key findings are summarized in the conclusion.

\section{ENTERPRISE SYSTEMS AND IMPLEMENTATION ISSUES}

What differentiates ES from other types of large information systems? ES are characterized by four main traits. First and foremost, ES integrate the information flows within the organization. Furthermore, ES are commercial packages (i.e., vendors release them. Third, ES consist out of best practices. And final, since every organization is in essence unique, some assembly will always be required; ES integrate the software, not the computing platform.

Due to the sheer size and reach of ES packages, complications during implementation quickly arise. Most notorious is the impact on the organization as a whole. Davenport (1998) points out that ES have profound business implications, and offloading responsibility to technologists is particularly dangerous as technical challenges are not the main reason ES fail. Companies often fail to reconcile the technological imperatives of the ES with the business needs of the enterprise itself. Also, the business often must be modified to fit the system (Davenport, 1998). This means the organizations' business processes need to be reengineered to fit the best practices that comprise the system, which considerably adds to the expense and risk of introducing ES (Kumar \& Van Hillegersberg, 2000; Markus \& Tanis, 2000). Moreover, vendors try to structure the systems to reflect best practices, but it is the vendor, not the costumer that is defining what "best" means (Davenport, 1998). This means the adopting organization is dependent on the vendor for updates of the package (Markus \& Tanis, 2000). Furthermore, achieving full integration depends a lot on the configuration of the system and the choice for installing 
just one system instead of modules from multiple vendors (Markus \& Tanis, 2000). Still, in addition to having important strategic implications, ES also have a direct and paradoxal impact on a company's organization and culture. On one hand organizations are capable to streamline their management structures, creating flatter, more flexible, and more democratic organizations. On the other hand, they also involve the centralization of control over information and the standardization of processes, which are qualities more content with hierarchical, commandand-control organizations with uniform cultures (Davenport, 1998).

Next to these organizational impacts of ES, organizations also have good reasons not to adopt ES or even abandon ES implementation. Two reasons that are often mentioned is that the packages in the market lack fit with the specific needs of an organization, and that ES have the tendency to inhibit flexibility, growth, and decentralized decision making. Also important are the available alternatives, for instance sophisticated data warehousing or using middleware to change a system's architecture (Markus \& Tanis, 2000). To sum up, the main reasons for not adopting a system also hold for ES: high cost, no competitive advantage, and resistance to change.

\section{INFORMATION SYSTEMS IMPLEMENTATION IN THE PUBLIC SECTOR}

Next to the specific characteristics of ES implementation, information systems implementation in the public sector differs from information systems implementation in business. Numerous studies have been conducted to define the differences between the public and private sector, however, still one of the most influential in the field of information systems is the article by Rainey, Backoff, and Levine (1976). They distinguish three main characteristics in which public sector organizations differ from private sector organizations. Usually, public sector organizations are less exposed to the market, resulting in: less incentive for effectiveness, more legal and formal constraints, and higher political influences. Also, due to the unique sanctions and coercive power of government, demands on fair, honest, responsive, accountable, and honest behaviors by public managers are higher. And, public managers need to handle complex-possibly conflicting-criteria, while there is high turnover of politically appointed top managers.

Based on these distinctions Caudle, Gore, \& Newcomer (1991) made a study on key information systems management issues for the public sector. Unique and paramount for the public sector is the linking of IS plan- ning and budgeting as a replacement for the allocative mechanism of the market, and freely transferring a technology from one agency to another contrast sharply with private sector IS development. Issues that already have peaked in the private sector but are still on the rise in the public sector are the integration of technologies, enduser computing, and office automation. This lag is most probably caused by limitations by government red tape and accountability requirements (Caudle, Gorr, \& Newcomer, 1991). The authors end with some theoretically deriving some potential issues. Public managers should be more inclined to develop new information technologies than their politically appointed superiors. And, the more red tape the organization has, the more flexible the information technology employed should be.

Even a decade later, Brown (2001) worries about the elementary level of issues mentioned in a UK government report on the delivery of government IT projects. The list of issues that need more attention in the UK public sector-but most probably in all Western governmentsincludes: commitment of senior management; identifying the end users and their needs; skilled and knowledgeable project managers; breaking down a project into manageable sub-components; adequate training; importance of IT contract definition, negotiation and management; contingency plans in place; and a post-implementation review (Brown, 2001). All these lessons can be found in basic handbooks on IT implementation. Another important lesson rings a bell: key decisions about IT systems are business decisions not technical ones (Brown, 2001; cf., Davenport, 1998).

\section{PUBLIC SECTOR ENTERPRISE SYSTEMS IMPLEMENTATION}

Very few studies have been conducted on ES implementation in the government. After a search for combinations of the words "government" or "public sector," with "enterprise system," "enterprise systems"or"enterprise resource planning" in the "Web of Science" and "Business Source Elite" databases a number of scientific articles appeared. A further selection was made by reading these articles and removing those that included studies in which ES implementation in the government was not the main topic of the study (Ashbaugh \& Miranda, 2002; Bannister, 2001; Boudreau \& Robey, 2005; Yen \& Sheu, 2004), and those that where conducted in a university setting (Scott \& Wagner, 2003; Siau \& Messersmith, 2003). We removed studies on academic administrations from our selection, as universities are not very representative for government organizations such as ministries, municipalities, executive agencies, etc. Finally, four ar- 
ticles remained (Chang \& Gable, 2002; Gulledge \& Sommer, 2003, 2004; Kumar, Maheshwari, \& Kumar, 2002). Most noticeable, besides the few studies conducted in total, is that all articles have been published after 2000. It appears that the study of public sector ES implementation is still in its infancy.

The two articles by Gulledge and Sommer $(2003,2004)$ report on an U.S. Department of Defense installation management enterprise implementation, and two U.S. NAVY implementations. The 2003 article differs from the other articles in the sample as the authors argue that there is nothing special about public sector business processes that insulate them from modern private sector management methods. However, in their more recent article they stress that in the private sector the implementing organization usually owns all of the business processes within its domain, while in the public sector this is not always the case. This can lead to a "split instance": multiple standard software solutions are implemented in a domain that requires a single instance. Gulledge and Sommer argue that this problem is political and driven by the desire of senior management to preserve organizational stovepipes. Bannister (2001) also emphasizes the importance of breaking down specialized vertical system to provide an integrated service to the citizen. Currently, for instance Gortmaker and Janssen (2004) are studying opportunities for business process orchestration in the public sector.

The other two articles (Chang \& Gable, 2002; Kumar, Maheshwari, \& Kumar, 2002) take a more factor oriented approach as they provide us with vast lists of (sub-) issues. Both studies used surveys to gather their data. Chang and Gable studied five Australian government agencies, while Kumar et al. focused on 10 Canadian government organizations. Chang and Gable choose to use a modified Delphi technique to derive major and sub issues and have respondents weigh the major issues. Unexpectedly, they found very scarce influence of organizational context, including politics. Next to problems with reporting functionality and security, mainly human aspects were problematic. Examples were that few people understood the system beyond a single module, inadequate training, and a lack of understanding between agency staff and implementation personnel.

Kumar et al. based their survey on three of the four phases in the ERP Experience Cycle of Markus and Tanis (2000). The onwards and upwards phase was not studied as none of the organizations in their sample had reached this stage (!). Kumar et al. provide the percentage of respondents that said they had encountered these specific issues. From their research, above all, cost escalation arises as a major issue, whereas human aspects, primarily in the form of training play an important role too. Also, modifying the software and developing add-ons countered a number of ERP limitations. Surprisingly, they found that very few organizations reported changes in organizational structures to support the new systems.

\section{FUTURE TRENDS}

It is important to consider that ES are still evolving in functionality, service arrangements, terminology, andperhaps most interesting — architecture (Markus \& Tanis, 2000). Two future developments in the architecture domain stand out most. One is the evolution of extended ES towards including interorganizational processes such as supplier and customer relation management (Kumar \& Van Hillegersberg, 2000). The other is a componentbased strategy that would rely on a minimal ERP backbone together with a variety of domain-specific components (see Sprott, 2000). The organization is then responsible for the selection, design or development of their components. In this manner ES will become much more flexible than they are nowadays. Other future developments are the move from transaction data to other types of documents (e.g., multimedia documents, and the move from transaction processing to decision support, data mining, and executive information systems) (Kumar \& Van Hillegersberg, 2000).

Additionally, a recent global study among different sectors found that the organizations that already adopted ES, have still fully obtained the promised benefits (Davenport, Harris, \& Cantrell, 2002, 2004). The researchers emphasize the need to further integrate, optimize, and informate. Better integration can be achieved by unifying and harmonizing ES, data, and processes with the environment, and better connecting units and processes, as well as with customers and suppliers. Better optimization is reached by standardizing processes to fit best practices, and to fit processes with strategy and systems. And, organizations need to informate: using information to transform work, to support business analysis, and for decision-making needs. An example of an opportunity for government improvement found in this study, was that government organizations were ranked second-highest with management reporting and metrics functionality installed, but failed to utilize this information as they also have the lowest number of performance management functionality installed compared to the business sectors.

A lot of opportunities for public sector ES implementation research exist as the field is still in its infancy. The underlying dynamics of resistance to ES implementation need to be mapped to get past lists of major issues as present in two of the four articles. In the first place, studies in the public sector will add to the general ES implementation literature by contextualizing the findings of previous studies. Will these findings hold in a public sector environment? Furthermore, there needs to be 
research into differences between specific governmental sectors. Additionally, the public sector can be fruitful ground for studies into professional or service-oriented organizations. Of course, the important venues Markus and Tanis (2000) mentioned, can just as well be studied in the public sector: financial costs and risks; technical issues; managerial issues; IT adoption, use and impacts; and integration. The Enterprise System phenomenon has strong conceptual links with just about every major area of information systems research. But, most rewarding might be the exemplary role government can play in pursuing a components-based strategy, due to the ease of technology transfer. Perhaps, components for government ES can be developed around the globe as open source software (see, Von Hippel \& Von Krogh, 2003).

\section{CONCLUSION}

A number of issues can be perceived as well in ES implementation as in public sector information systems implementation. Obviously, the implementation of any system must be seen in a broader perspective then solely technical. In addition, the integration of public sector IT is lagging compared to business. This might also explain the currently limited number of studies on ES implementation in the public sector. From the studies conducted specifically into ES implementation in the public sector we learn a number of things. Foremost, the problems encountered by government are quite similar to those encountered by business. However, a number of typical issues did arise in these studies. The integration of different information flows provided by ES might be terse due to the public sectors' organizational stovepipes. Also, the ES software needed to be modified in half the organizations, which means higher investments needed to be made and implementation became more complicated. Also, very few organizations reported changes in organizational structure to support the ES, also the availability and retention of skilled staff was problematic, both possibly inhibited by red tape (see Bozeman, Reed, \& Scott, 1992) or other public sector constraints. It is therefore important for public sector organizations to negotiate increased attention on government specific needs for ES (Kumar, Maheshwari, \& Kumar, 2002).

Interesting is the statement that there is a theoretical relationship between the amount of red tape and the flexibility of the information technology used (Caudle, Gorr, \& Newcomer, 1991). This would either mean that reengineering with $E S$ could abolish vast quantities of red tape, or that public sector ES need to be flexible to adapt to rule-bound public sector organizations. Either viewpoint currently sounds quite utopian. Yet, the most prom- ising future venue might be a component-based strategy, as government is usually more rule-bound and technology sharing should be easier than in business. In this way government can leave its lagging position and leap jump to become a frontrunner in the ES field.

\section{REFERENCES}

Ashbaugh, S., \& Miranda, R. (2002). Technology for human resources management: Seven questions and answers. Public Personnel Management, 31(1), 7-20.

Bannister, F. (2001). Dismantling the silos: Extracting new value from it investments in public administration. Information Systems Journal, 11(1), 65-84.

Boudreau, M., \& Robey, D. (2005). Enacting integrated information technology: A human agency perspective. Organization Science, 16(1), 3-18.

Bozeman, B., Reed, P., \& Scott, P. (1992). Red tape and task delays in public and private organizations. Administration and Society, 24(3), 290-322.

Brown, T. (2001). Modernisation or failure? IT development projects in the UK public Sector. Financial Accountability and Management, 17(4), 363-381.

Caudle, S. L., Gorr, W. L., \& Newcomer, K. E. (1991). Key information systems management issues for the public sector. MIS Quarterly, 15(2), 171-188.

Chang, S., \& Gable, G. G. (2002). A comparative analysis of major ERP life cycle implementation, management, and support issues in Queensland government. Journal of Global Information Management, 10(3), 36-54.

Davenport, T. H. (1998). Putting the enterprise into the enterprise system. Harvard Business Review, 76(4), 121131.

Davenport, T. H., Harris, J. G., \& Cantrell, S. (2002). The return of enterprise solutions: The director's cut. Cambridge, MA: Accenture Institute for Strategic Change.

Davenport, T. H., Harris, J. G., \& Cantrell, S. (2004). Enterprise systems and ongoing process change. Business Process Management Journal, 10(1), 16-26.

Gortmaker, J., \& Janssen, M. (2004). Business process orchestration in e-government: A gap analysis. Paper presented at the $15^{\text {th }}$ IRMA International Conference, May 23-26, New Orleans, LA.

Gulledge, T. R., \& Sommer, R. A. (2003). Public sector enterprise resource planning. Industrial Management and Data Systems, 103(7), 471-483. 
Gulledge, T. R., \& Sommer, R. A. (2004). Splitting the SAP instance: Lessons on scope and business processes. Journal of Computer Information Systems, 44(3), 109115.

Kumar, K., \& Van Hillegersberg, J. (2000). ERP: Experiences and evolution. Communications of the ACM, 43(4), 23-26.

Kumar, V., Maheshwari, B., \& Kumar, U. (2002). ERP systems implementation: best practices in Canadian government organizations. Government Information Quarterly, 19(2), 147-172.

Markus, M. L., \& Tanis, C. (2000). The enterprise systems experience: From adoption to success. In R. W. Zmud (Ed.), Framing the domains of IT research: Glimpsing the future through the past (pp. 173-207). Cincinatti, OH: Pinnaflex Educational Resources.

Rainey, H. G., Backoff, R., \& Levine, C. (1976). Comparing public and private organizations. Public Administration Review, 36(2), 233-244.

Scott, S. V., \& Wagner, E. L. (2003). Networks, negotiations, and new times: The implementation of enterprise resource planning into an academic administration. Information and Organization, 13(4), 285-313.

Siau, K., \& Messersmith, J. (2003). Analyzing ERP implementation at a public university using the innovation strategy model. International Journal of Human-Computer Interaction, 16(1), 57-80.

Sprott, D. (2000). Componentizing the enterprise: Application packages. Communications of the ACM, 43(4), 6369.

Von Hippel, E., \& Von Krogh, G. (2003). Open source software and the "private-collective" innovation model: Issues for organization science. Organization Science, 14(2), 209-223.

Yen, H. R., \& Sheu, C. (2004). Aligning ERP implementation with competitive priorities of manufacturing firms: An exploratory study. International Journal of Production Economics, 92(3), 207-220.

\section{KEY TERMS}

Component-Based Strategy: Strategy based on agreed standard interfaces that allow the disparate sets of parts to be assembled, to interoperate and to be upgraded with newer parts that conform to the same interface.

Enterprise System (ES): Configurable information system package sold by a vendor, which integrates information and information-based processes within and across functional areas in an organization based on best practices.

ES Best Practices: The standard templates for generic business processes instilled in an ES. These best practices may differ quite substantially from the way any particular organization does business and implicitly demand a certain level of process reengineering to reach cross-functional efficiency and effectiveness.

ES Implementation: The entire adoption process of an ES system: starting with the idea of introducing an ES, running the introduction project, stabilizing the system, and onward; maintaining the system, supporting the users, getting results, and upgrading.

ES Functionality: A business function supported by a software module in an ES. Examples of functions are finance and accounting, human resource, supply chain, customer information, and many more.

ES Module: A packaged functional assembly of software for use with other such assemblies within an ES. See ES functionality.

ES Package: A package purchased or leased from ES software vendors (like SAP, Peoplesoft, Oracle, Baan, JD Edwards, etc.) instead of being developed in-house from scratch. This means implementers of an ES often need to adjust the organization's ways of working to fit the package, they enter into long-term relationships with software vendors, and they depend on the vendor for continued enhancement of their package. 